\title{
Caesarean delivery of a Western Lowland gorilla with fetal distress and suspected pre-eclampsia
}

\author{
Sophie L. Walter ${ }^{*}$, Aamna Ali ${ }^{1}$, Rowena Killick², Charlotte Day², \\ Michelle Barrows ${ }^{2}$, David J. Cahill ${ }^{3}$
}

\begin{abstract}
${ }^{1}$ Department of Obstetrics and Gynaecology, St Michaels Hospital, Southwell Street, Bristol, United Kingdom ${ }^{2}$ Department of Veterinary Medicine, Bristol Zoo Gardens, Bristol, United Kingdom

${ }^{3}$ Head, Academic Unit of Obstetrics and Gynaecology, University of Bristol, St Michaels Hospital, Southwell Street, Bristol, United Kingdom
\end{abstract}

Received: 02 May 2018

Accepted: 29 May 2018

\section{*Correspondence:}

Dr. Sophie L. Walter,

E-mail: sophie.walter@uhbristol.nhs.uk

Copyright: (c) the author(s), publisher and licensee Medip Academy. This is an open-access article distributed under the terms of the Creative Commons Attribution Non-Commercial License, which permits unrestricted non-commercial use, distribution, and reproduction in any medium, provided the original work is properly cited.

\begin{abstract}
Pre-eclampsia is a well-recognised complication of human pregnancy however case reports suggest that it also affects non-human primates. The authors present the case of a primigravid western lowland gorilla (Gorilla gorilla gorilla) who developed behavioural changes, significant proteinuria, and ultrasound features of suspected fetal distress at term, three days prior to her estimated due date. A working diagnosis of pre-eclampsia was made, and the baby was delivered by emergency caesarean section. In spite of a prolonged recovery complicated by sepsis, anaemia and persistent proteinuria in the mother, both mother and baby made a good recovery. This case highlights how the application of basic principles of obstetric medicine and collaboration between obstetricians and veterinarians in the care of captive gorillas resulted in the successful management of pregnancy complications.
\end{abstract}

Keywords: Cesarean, Gorilla, Pre-eclampsia

\section{INTRODUCTION}

Pre-eclampsia is a leading cause of maternal and neonatal morbidity and mortality worldwide. ${ }^{1}$ Manifestations include hypertension, proteinuria, fetal growth restriction, HELLP syndrome and eclampsia.

Case reports of hypertensive proteinuric syndromes in non-human primates suggest that pre-eclampsia may not be exclusive to humans. In Patas monkeys (Erythrocebus patas), the spontaneous onset of a disease characterised by oedema, hypertension and proteinuria was described in late gestation. ${ }^{2}$ The incidence was highest amongst primiparous monkeys and was associated with poor maternal and fetal outcome. Renal biopsies taken following uterine ischaemia in baboons (Papio anubis) showed microscopic changes similar to pre-eclampsia in humans. ${ }^{3}$ Two case reports describe convulsions associated with oedema in lowland gorillas in the latter stages of pregnancy, including one with evidence of placental abruption and infarction. ${ }^{4-5}$

The pathophysiology of pre-eclampsia in humans relates to defective deep trophoblastic invasion and spiral artery remodelling of the developing placenta. In healthy cases, extravillous trophoblasts invade the maternal decidua and uterine arteries resulting in lower resistance and increased blood flow. Analysis of placental tissue in early and midtrimester lowland gorillas has shown that this species shares a similar pattern of deep trophoblast invasion to humans. ${ }^{6}$ Gene-clusters associated with increasing preeclampsia risk in humans have been found in primates (chimpanzee, gorilla and orangutan) in whom deep trophoblast invasion has been identified. ${ }^{7}$ Additionally, analysis of placental tissue in a lowland gorilla who developed convulsions late in pregnancy showed 
evidence of syncytial knotting of the chorionic villi, a feature seen in human placental tissue in cases of preeclampsia. $^{4}$

Collaboration between specialists in human obstetrics and veterinarians in the management of captive gorilla pregnancies and complications was first described in 1978, when an infant gorilla was delivered via caesarean section in an attempt to prevent infanticide by the mother. ${ }^{8}$ Magnesium sulphate has been used successfully in cases of suspected eclampsia in lowland gorillas. ${ }^{4-5}$ Operative delivery using a vacuum has been performed in a case of prolonged second stage of labour. ${ }^{9}$ Hysterectomies for reproductive tract neoplasia have also been performed in non-obstetric cases. ${ }^{10}$ No previous case reports have been published describing obstetric intervention in a case of fetal distress.

The authors describe how principles of human obstetric medicine were applied and collaborative working between obstetricians and veterinarians facilitated the management of fetal distress and a suspected case of preeclampsia in a western lowland gorilla (Gorilla gorilla gorilla).

\section{CASE REPORT}

A primigravid western lowland gorilla kept at Bristol Zoo Gardens spontaneously conceived at 11 years of age. She had no known underlying medical conditions and her pregnancy progressed without complication.

Three days prior to her estimated due date (calculated from an average gestational length of 255 days,) her keepers noted that she became increasingly lethargic, anorexic and irritable. ${ }^{11}$ She adopted postures indicating that she had abdominal pain. This prompted the veterinary staff to undertake investigations.

Analysis of a free catch urine sample collected by keepers showed evidence of proteinuria, confirmed by a urine protein: creatinine ratio of 0.16 . To facilitate further diagnostic investigations, general anaesthesia was required. On February 12th, 2016 she was sedated using $400 \mathrm{mg}$ ketamine and $4 \mathrm{mg}$ medetomidine administered via remote intramuscular injection (using a dart gun), first given at $14.30 \mathrm{~h}$. A further $400 \mathrm{mg}$ ketamine and $4 \mathrm{mg}$ medetomidine given intramuscularly by hand injection rendered her deeply sedated and following another hand injection of $100 \mathrm{mg}$ ketamine she was fully anaesthetized, and it was deemed safe to transfer her to the veterinary procedure room. Once there she was given $8 \%$ sevoflurane in oxygen by mask to enable endotracheal intubation with a $7.5 \mathrm{~mm}$ cuffed tube, although this proved challenging, and a further intramuscular injection of 100mg ketamine was given when she started to regain consciousness. Profuse vomiting of green-brown fluid occurred at the time of intubation. Anaesthesia was maintained with 6-8\% sevoflurane, and later 3-5\% isoflurane in oxygen. Vascular access was obtained for blood draw and administration of intravenous fluid therapy. Blood analysis showed a haemoglobin concentration of $112 \mathrm{~g} / \mathrm{dl}$ and normal biochemistry. Acid base status was within the normal range.

The change in behaviour, continuing presence of marked proteinuria and ultrasound findings led to a diagnosis of suspected fetal distress secondary to underlying preeclampsia. Pre-existing renal disease could not be excluded at this stage.

The ultrasound findings were relayed to the veterinary team and a considered decision was made to proceed with delivery. On vaginal examination the cervix was soft but closed. Although the spontaneous onset of labour within the next 24 hours remained a possibility, concerns were growing regarding the deteriorating maternal condition and suspected fetal distress. Induction of labour using prostaglandins was not considered possible due to logistical difficulties and the inability to monitor the fetus. Therefore, the decision was made to perform an emergency caesarean section.

Prior to the caesarean section the bladder was catheterised, though with some difficulty. The urethra was located correctly on a transverse ridge on the anterior vaginal wall $2 \mathrm{~cm}$ from the introitus (its normal position in great apes). Repeat urinalysis of the urine showed significant proteinuria, reinforcing a diagnosis of preeclampsia. A transverse lower abdominal incision akin to a Pfannenstiel incision was made and the obstetric team dissected through the thick subcutaneous tissue to the rectus sheath. This was divided, and the peritoneal cavity opened bluntly. The vesico-uterine adhesions observed in other great ape caesarean sections and described in the literature were not observed (Personal communication, $\mathrm{P}$ Foster). ${ }^{8}$

The bladder was reflected, and a lower uterine segment identified and incised. The membranes were ruptured, Wrigley's forceps were applied to the fetal head and the fetus was delivered through the anterior abdominal wall at $17.15 \mathrm{~h}$. The female baby showed no signs of spontaneous respiratory effort therefore resuscitation was commenced. Intravenous oxytocin was injected, and the placenta was delivered manually. The uterine incision was closed in 2 layers. Interrupted sutures closed the thick layer of subcutaneous tissue and the skin was closed with subcuticular sutures. Total estimated blood loss was between $200-300 \mathrm{ml}$. Throughout the procedure the mother's oxygen saturation remained between 91-98\% and pulse between $80-88$ beats per minute. Blood pressure readings were normal throughout.

The newborn gorilla required prolonged resuscitation, intubation and ventilation due to apnoea although she maintain a cardiac output throughout. Thereafter she recovered well and was feeding from bottles the following day. She was hand-reared whilst the mother continued her recovery. 
The mother was fully mobilising by the third day after her caesarean and her initial recovery was uncomplicated. She continued antibiotics for suspected aspiration during intubation and metoclopramide for a suspected ileus. However, persistent proteinuria was noted.

Three weeks post-operatively, the mother became increasingly lethargic and appeared anaemic based on mucus membrane colour. Her oral food intake was minimal. Under general anaesthesia, blood analysis showed a severe poorly regenerative anaemia, with a haemoglobin of $32 \mathrm{~g} / \mathrm{dl}$ (95-156 g/dl), PCV of $10 \%$ (30$49.6 \%$ ) and elevated inflammatory markers with WCC $17 \times 109 / 1$ (3.5-16.4 $\mathrm{x} 109 / 1)$ and $\mathrm{C}$ reactive protein $110 \mathrm{mg} / \mathrm{l}(0-10)$. Her platelet count and fibrinogen were normal. A trans-abdominal and thoracic ultrasound scan showed bilateral pleural effusions and a pericardial effusion. There was no evidence of intra-abdominal haemorrhage. The bladder was thickened suggesting cystitis however the kidneys were normal. Two days later, after cross-matching with another gorilla, the mother was transfused with $450 \mathrm{mls}$ of whole blood, intravenous iron and 40000 units of erythropoietin subcutaneously. She was continued on broad spectrum antibiotics for suspected sepsis. Analysis of free catch urine showed persistent significant proteinuria and haematuria. Glomerulonephritis and haemolysis were suspected and she was treated with high dose prednisolone (50mg twice daily.) Erythropoietin, iron and folic acid supplements continued.

After six months, the haemoglobinuria resolved and she was weaned off the steroids. Her demeanour, behaviour and appetite had returned to normal and the body condition lost during illness was regained. At the time of writing she continues to do well.

\section{DISCUSSION}

The western lowland gorilla is a critically endangered species. Successful breeding in captivity not only provides valuable information for researchers but is also key to conservation of the species.

Case reports of clinical syndromes and placental analysis suggest that pre-eclampsia is not exclusive to humans. However, diagnosing pre-eclampsia in non-human primates is logistically challenging. Observations and investigations which are routinely performed in the human population usually require a general anaesthetic in the primate population. Hallmark symptoms such as headache, visual disturbance or abdominal pain cannot be easily assessed and parameters in ultrasound assessment are not validated.

In our case, the gorilla displayed definite evidence of worsening proteinuria and behavioural changes in the latter stages of her pregnancy. Given that she had no preexisting medical conditions, it was reasonable to assume a diagnosis of pre-eclampsia. Regrettably, no placental histology was performed to support this diagnosis, though authors know that liver enzymes were normal, as were platelets on a film at the time of delivery. At present, there are no known parameters for the ultrasound assessment of a healthy gorilla fetus. Authors know that the mother's clinical condition was deteriorating, and the gorilla baby required prolonged resuscitation following delivery; authors are therefore assuming that the fetus being unresponsive with minimal liquor and bradycardia were indicators of fetal distress, and the fetus might not have survived vaginal delivery. The anaesthetic did of course add to the difficulty in resuscitation. The gorilla baby has minimal signs of any developmental delay in behaviour or in troop activity; ketamine may have some protective role in reducing the effects of cerebral oedema and later damage (personal communication, Prof P Dunn; 12)

Interestingly, in the weeks following her delivery, the gorilla mother had proteinuria with haematuria. Although her renal biochemistry remained within the normal range, an underlying renal tract disease was suspected, and she was commenced on high dose prednisolone. Her proteinuria and haematuria subsequently resolved over a 6-month period. Cases of renal pathology have been reported in other great apes. A 39-year-old western lowland gorilla developed renal failure secondary to chronic interstitial nephritis. ${ }^{13}$

A further case report described a fatal case of renal tubular nephrosis. ${ }^{14}$ Comparative pathology of ageing great apes describes two deaths related to pyelonephritis. ${ }^{15}$ Proteinuric hypertension in a pregnant baboon (Papio Anubis) was diagnosed as pre-eclampsia, however subsequent renal biopsy confirmed glomerulonephritis as the underlying pathology. ${ }^{16}$ It therefore remains to be confirmed whether the gorilla had a pre-existing renal pathology with superimposed preeclampsia at the latter stages of her pregnancy, or whether the proteinuria was indicative of renal pathology alone. Causes of renal diseases in other great apes with haemoglobinuria are found generally only in the aged populations, and then in post-mortem findings. ${ }^{15}$

Sufficient similarities in gorilla reproductive anatomy allowed the obstetric team to clinically assess and perform a caesarean section using techniques from human obstetrics. A transverse incision in the lower anterior abdominal wall was made, the subcutaneous tissue was dissected, and the rectus sheath divided in the same way as in a human caesarean delivery.

Although previously described in the literature, vesicouterine adhesions were not identified, and the bladder was not adherent to the anterior aspect of the uterus, allowing easy dissection of the uterovesical fold and identification of a lower uterine segment, which has not previously been recognised. Other key anatomical differences were confirmed: the urethral meatus was identified on a transverse ridge on the anterior vaginal 
wall $2 \mathrm{~cm}$ from the introitus and the subcutaneous tissue was fibrous and deep, requiring a more strenuous dissection.

\section{ACKNOWLEDGMENTS}

The authors would like to acknowledge the keepers and Veterinary staff at Bristol Zoo Gardens who played a significant role in the care of both mother and baby.

\section{Funding: No funding sources}

Conflict of interest: None declared

Ethical approval: All medical records were provided with permission from the veterinarian staff at Bristol Zoo Gardens. No medical ethics committee approval was required in the preparation of this case report.

\section{REFERENCES}

1. WHO. WHO recommendations for prevention and treatment of pre-eclampsia and eclampsia: Implications and actions. 2013. Available at: http://www.who.int/reproductivehealth/publications/ maternal_perinatal_health/program-actioneclampsia/en/

2. Palmer AE, London WT, Sly DL, Rice JM Spontaneous preeclamptic toxemia of pregnancy in the patas monkey (Erythrocebus patas). LAB. ANIM. SCI. 1979;29(1):102-106

3. Cavanagh D, Rao PS, Tung KSK, Gaston L. Eclamtogenic toxaemia: the development of an experimental model in the subhuman primate, Am J Obstet Gynecol. 1974

4. Baird Jr. JN Eclampsia in a lowland gorilla. Am J Obstet Gynecol. 1981;141(3):345-6

5. Thornton JG, Onwude JL. Convulsions in pregnancy in related gorillas. Am J Obstet Gynecol. 1992;167(1):240-1

6. Pijnenborg R, Vercruysse L, Carter AM. Deep trophoblast invasion and spiral artery remodelling in the placental bed of the lowland gorilla. Placenta. August 2011;32(8):586-91

7. Crosley EJ, Elliot MG, Christians JK, Crespi BJ Placental invasion, preeclampsia risk and adaptive molecular evolution at the origin of the great apes: Evidence from genome-wide analyses. Placenta. February 2013;34(2):127-32.
8. O'Grady JP, Davidson JE, Thomas WD, Esra GN, Gluck L, Kulovich MV. Cesarean delivery in a gorilla. J Ame Vet Med Assoc. 1978 Nov;173(9):1137-40.

9. Cole RE. Obstetric management of a protracted labor in a captive western lowland gorilla. Am J Obstet Gynecol. 2000;182:1306-11.

10. Cooper, John E, and Gordon Hull. Gorilla Pathology and Health, edited by John E Cooper, and Gordon Hull, Elsevier Science, 2016. ProQuest Ebook Central

11. Harcourt A, Stewart K, Fossey D. Gorilla reproduction in the wild. In: Graham, C. (Ed.), Reproductive Biology of the Great Apes: Comparative and Biomedical Perspectives. Academic Press, New York, NY;1981:265-279. Cooper, John E, and Gordon Hull.

12. Chang EI, Wood CE. Ketamine attenuates the ACTH response to hypoxia in late-gestation ovine fetus. Neonatology. Jun 2015;107(4):249-255.

13. Paixa o TA, Tinoco HP, Malta MdeC, Teixeira da Costa MEL, Soave SA, Pessanha AT et al Pathological findings in a captive senile western lowland gorilla (Gorilla gorilla gorilla) with chronic renal failure and septic polyarthritis. Braz $\mathrm{J}$ Vet Pathol. 2014;7(1):29-34.

14. Paal S, Kasza L, Boros G, Fabian L. Tubular nephrosis-possible cause of death of a gorilla. Verh. Ber. Erkrg. Zootiere. 1982;24:205-8.

15. Lowenstine LJ, McManamon R, Terio KA. Comparative pathology of aging great apes: bonobos, chimpanzees, gorillas, and orangutans. Vet Pathol. 2016 Mar;53(2):250-76.

16. Ramsay MM, Tame JD, Winter JA, Carbone LG, Schlafer $\mathrm{OH}$, Nathanielsz PW. Proteinuric hypertension in a pregnant baboon: Was this preeclampsia?. J Med Primatol. 1997 Aug 1;26(4):20712.

Cite this article as: Walter SL, Ali A, Killick R, Day

C, Barrows M, Cahill DJ. Caesarean delivery of a

Western Lowland gorilla with fetal distress and suspected pre-eclampsia. Int J Reprod Contracept Obstet Gynecol 2018;7:2933-6. 